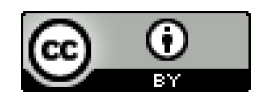

Esta obra está sob o direito de Licença Creative Commons Atribuição 4.0 Internacional.

\title{
PSICOLOGIA DA EDUCAÇÃO E SUAS INTERVENÇÕES NO PROCESSO DE ENSINO APRENDIZAGEM
}

\author{
Edivania Maria Silva de Lima ${ }^{1}$
}

\section{RESUMO}

Este trabalho visa contribuir para uma melhor compreensão sobre o processo de aprendizagem no âmbito escolar. A denominação "teorias de aprendizagem" se refere a um conjunto de enfoques e perspectivas teóricas diferenciadas e/ou complementares que procuram oferecer explicações gerais sobre os elementos e os fatores envolvidos no processo de ensino aprendizagem. A pesquisa buscou identificar e analisar criticamente as diversas teorias sobre o processo de aprendizagem com o objetivo de refletir e desenvolver práticas educativas histórico-críticas, criativas e inovadoras, tendo em vista a diversidade de situações, condições e necessidades educativas no espaço escolar. Através da pesquisa bibliográfica, fazendo uma análise crítica e reflexiva com base em suporte teórico que permita efetuar questionamento crítico para sua prática educativa. O estudo mostra a importância de diversas teorias que permite uma reflexão sobre a prática docente em sala de aula, de forma que o educador seja capaz de identificar e utilizar as técnicas e os conceitos mais adequados para estimular o processo de ensino aprendizagem. E assim o desenvolvimento cognitivo de cada educando de modo mais produtivo, tendo em vista cada situação de aprendizagem na sociedade onde está inserido.

Palavras-chave: Psicologia da Educação. Intervenções. Ensino Aprendizagem.

Submetido em dezembro de 2019 e aceito em janeiro de 2020.

\footnotetext{
${ }^{1}$ Mestranda em Ciências da Educação, Formação Educacional Interdisciplinaridade e Subjetividade - UNASUR, Pós Graduação em Psicopedagogia Clínica e Institucional pela - FACINTER, 2008, Graduada em Pedagogia séries iniciais - UNEAL - 2005.
} 


\section{INTRODUÇÃO}

O conhecimento como elemento fundamental na construção dos destinos da humanidade tem sido cada vez mais evidenciado e propagado no contexto da sociedade atual. Ao tentarmos responder à questão de ensino aprendizagem, temos em mente que aprender significa sermos capazes de fazer algo que não fazíamos, ou seja, aprendemos, a ler, a escrever, a calcular ou a utilizar a internet.

Para muitos docentes, o ensino aprendizagem é confundido com suas manifestações exteriores e os resultados que em si estas geram. Normalmente o professor não compreende adequadamente o que se passa de fato no interior do sujeito quando ele aprende. Por exemplo, para alguns autores, a aprendizagem ocorre por meio da repetição e pela imitação, referindo-se apenas a comportamentos observáveis e mensuráveis; nada fala, portanto sobre as operações mentais próprias do processo de construção do conhecimento que leva à aprendizagem (WOOLFOLK, 2000).

O conceito de ensino aprendizagem é complexo porque envolve a interação de diversos fatores e processos através dos quais compreendermos conceitos de temas específicos, como matemática, português, desenho e outros.
Pilett (1999) afirmará que “[...] a Psicologia da Educação procura utilizar os princípios e as informações que as pesquisas psicológicas oferecem acerca do comportamento humano, para tornar mais eficiente o processo ensino-aprendizagem". Assim é preciso conhecer como funciona o comportamento do indivíduo para que o conhecimento seja bem sucedido.

Estamos sempre aprendendo, intencionalmente ou não durante toda vida. Como por exemplo, os bebês aprendem a brincar, os adolescentes aprendem a tocar instrumentos musicais, e os adultos podem aprender uma nova dieta de alimentação ou um novo estilo de vestir.

Na realidade, o aprendizado consiste em uma mudança relativamente persistente no comportamento do indivíduo devido à experiência. Esta abordagem, portanto, enfatiza de modo particular a maneira como cada indivíduo interpreta e tenta entender o que acontece. $\mathrm{O}$ indivíduo não é um produto relativamente mecânico do ambiente, mas um agente ativo no processo de aprendizagem, que procura de forma deliberada processar e categorizar o fluxo de informações recebido do mundo exterior (FANTANA, 1998, p. 157).

Portanto a aprendizagem não é a simples passagem da ignorância ao saber, sem resistências e sem conflitos. Nesse processo, acontece algo novo que não 
envolve uma simples reestruturação. Tratase, pois, de um fenômeno a partir do qual um sujeito toma para si uma nova forma de conduta, transforma a informação em conhecimento, hábitos e atitudes novas.

É importante entendermos que, para aprendizagem ocorrer, é necessário que haja uma interação ou troca de experiências do indivíduo com o seu meio ambiente ou comunidade educativa. As crianças, aprendem a partir da interação com os adultos e com crianças mais experientes. Por meio dessas interações, a criança vai construindo, gradativamente, significados para as suas ações, suas experiências e objetos ao seu redor (COLL, 1995). Essa construção de significados pressupõe a identificação de características, propriedades e finalidades para suas ações e experiências com fatos e objetos.

Existem pesquisas que visam descobrir e analisar como construímos o nosso conhecimento e desenvolvemos a inteligência, sem uma preocupação exclusiva com o processo de ensino aprendizagem. Entretanto, as explicações geradas pelas teorias da aprendizagem têm fornecido, por sua vez, subsídios para a compreensão de como aprendemos.

\section{METODOLOGIA}

A estratégia metodológica definida para este estudo foi uma revisão de
Algumas teorias conceituam aprendizagem de forma diferente porque compreendem o processo de aquisição do conhecimento de forma diferenciada.

Nesse sentido, podemos afirmar que o conhecimento dessas teorias, em particular no âmbito escolar, inspira o uso de estratégias sobre como o professor poderia estimular o desenvolvimento cognitivo e o processo de ensino aprendizagem do seu educando de forma mais produtiva e duradoura.

Consultando assim autores que tratem a respeito do tema para dar sustento ao estudo, podendo ser realizada a pesquisa bibliográfica e exploratória porque se baseia na leitura o aprofundamento de informações e conhecimentos para um melhor aperfeiçoamento e comprovação do trabalho da Psicologia da Educação e suas intervenções no processo de ensino e aprendizagem.

Encontra-se aí, um estudo que busca ser um documento capaz de trazer uma luz para o educador, colaborando para sanar as dificuldades no processo de ensino aprendizagem e no âmbito educacional como um todo.

literatura tradicional, não sistemática, por meio de livros e documentos físicos e digitais, os quais foram analisados 
qualitativamente e definida as seguintes categorias temáticas: Qual a importância da psicologia da educação no processo de ensino?, a importância do psicopedagogo

\section{RESULTADOS E DISCUSSÕES}

Qual a importância da psicologia da educação no processo de ensino?

A Psicologia da Educação se concentra no estudo psicológico dos problemas cotidianos da educação dos quais se derivam princípios, modelos, teorias, procedimentos de ensino e métodos de pesquisa, análises estatísticas e procedimentos de mediação e avaliação apropriados para estudar o planejamento e os processos culturais e socialmente complexos das escolas (WITTTOCK, 1992 apud WOOLFOLK, 2000).

No entanto, é preciso olhar a sociedade ao seu redor, a cultura que está sendo desenvolvida para inserir uma forma de ensino aprendizagem mais participativo, união da comunidade escolar e do setor pedagógico para fortalecer esse desenvolvimento escolar. Resgatando assim, o direito de cidadania dentro da democracia social.

Nesta perspectiva a educação, ou o processo educativo, é um processo social que se desenvolve como um sistema, pelo qual se busca o ato de provocar ou produzir mudanças comportamentais naqueles indivíduos que se encontra em atividades frente ao desenvolvimento da aprendizagem e visão teórica de alguns pensadores da psicologia no processo de ensinoaprendizagem.

educativas. Pois o processo de ensinar, cabe a premissa de ser fator que proporciona conhecimentos e habilidades ao discente, sendo uma tarefa docente por excelência; onde a aprendizagem, ao contrário, referese aos procedimentos de aquisição de ditos conhecimentos e habilidades, sendo uma atividade executada por aquele que aprende e, portanto, "exclusividade" do discente. Onde o afeto influencia a velocidade com que se constrói o conhecimento, pois, quando as pessoas se sentem seguras, aprendem com mais facilidade (MACHADO, 1995 Apud Porto, 2007). Contudo, o conhecimento, como entendimento, processa-se de maneiras diferentes, as quais exercem uma influência significativa na aprendizagem formativa.

É importante reconhecer inicialmente que o objetivo não é dar conta de toda a teoria de aprendizagem, antes disso, ele se propõe a estabelecer as principais características daqueles que acredita que são as principais correntes teóricas no processo de ensinoaprendizagem.

Assim, deve-se abordar as teorias de aprendizagem por possibilitar que a informação recebida seja transformada em conhecimento construído. 
Somos como pescadores e nossas teorias são como redes. E não deixamos de lado de bom grado as redes com as quais algumas vezes pescamos pelo mero fato de que não servem para certos peixes ou em determinados mares, mas continuamente inventamos e tecemos novas redes e distintas e as lançamos à água, para ver o que pescamos com elas. Não desprezamos rede alguma e em nenhuma confiamos excessivamente, ainda que prefiramos carregar o barco com as redes mais eficazes e deixar no porto as de menos uso. E assim vamos navegando, renovando continuamente nosso arsenal de redes em função das características da pesca. (MOSTERÍN, 1987, p. 85 Apud PORTO, 2007, p. 13).

No entanto, dependendo do momento histórico, cultural ou mesmo econômico, entre outros, para se dar conta da tarefa de estudar as diferentes teorias da aprendizagem, teríamos de trabalhar diversas contribuições das mais diferentes áreas do conhecimento. Entretanto, como aprendizagem, para o nosso caso, tem a ver com o ser humano, quanto tentarmos e nos habitarmos a compreendê-lo, se é que isto é possível, mais apto estaremos a ajudá-lo nessa tarefa de aprender. Não é por outro motivo que a contribuição da psicologia é tão marcante nessa área teórica.

\section{A importância do psicopedagogo frente ao desenvolvimento da aprendizagem}

Compreendendo por formação todos os processos educativos, formais ou não, que permitem a intervenção do sujeito no universo, agindo crítica e responsavelmente, aprimorando pela ética nas relações, refletindo, avaliando e reformulando suas atitudes. Onde viveremos este momento de ressignificação do espaço escolar, para além das paredes de sala de aula e da transmissão de conteúdo, tornando a escola um lugar sintonizado com os direitos sociais contextualizado ao meio e ao tempo presente, nos quais os sujeitos constroem, com autonomia e em cooperação, seus conhecimentos e sua própria história.

Há muito tempo busca-se entender a queixa de não aprendizagem, demonstrando a necessidade de rever o motivo desencadeador que fecha no educando o foco de indicadores de supostas dificuldades de aprendizagem.

Relembrando as palavras de Souza Patto (2000, p. 46), quando diz que: "Essa versão que reduz o problema a uma causa física ou psíquica situada no interior do aluno ou no máximo na dinâmica de sua família, que isenta a escola e a deixa fora de foco, vem sendo discutida, criticada e já em grande medida superada...”.

Hoje sabemos que é no cotidiano da escola, nas práticas pedagógicas, 
metodológicas e nas relações estabelecidas neste contexto que se produzem a maioria das dificuldades de aprendizagem escolar.

A partir desse novo olhar, os psicopedagogos perceberam que o espaço da psicopedagogia não poderia ficar restrito ao clínico, mas que era necessário avançar até as instituições escolares promotoras de desenvolvimento de aprendizagem, objetivando tanto a avaliação quanto a intervenção possibilitando uma revisão do processo de ensinar-aprender como também na prevenção das dificuldades de aprendizagem.

Para Visca (1991, p. 15) “a ampliação no âmbito da psicopedagogia nos deu a possibilidade tanto do estudar o sujeito individual em profundidade, quanto extrapolar estes conceitos para macrossistema, os quais antes não tinham sido pesquisados".

Enquanto a psicopedagogia clínica tem como objeto de estudo a aprendizagem, a psicopedagogia institucional o coloca no ensinar/aprender, compreendendo-o não apenas como uma forma de ensinar para saber reproduzir o conhecimento, mas tornando o sujeito dessa ação capaz de vivenciá-la, contribuindo para a transformação da realidade social.

Sendo assim, o psicopedagogo pode atuar em diversas áreas, de forma preventiva e terapêutica, para compreender os processos de desenvolvimento e das aprendizagens humanas, recorrendo a várias estratégias objetivando se ocupar dos problemas que podem surgir.

O psicopedagogo pode desempenhar uma prática docente, envolvendo a preparação de profissionais da educação, ou atuar dentro da própria escola. Cabem também ao profissional detectar possíveis perturbações no desenvolvimento da aprendizagem: participar da dinâmica das relações da comunidade educativa a fim de favorecer o processo de integração e troca, promover orientações metodológicas de acordo com as características dos indivíduos e grupos, realizar processo de orientação educacional e ocupacional, tanto na forma individual quanto em grupo.

De acordo com Gonçalves (2002, p. 42) "as relações com o conhecimento, a vinculações com a aprendizagem, as significações contidas no ato de aprender, são estudados pela psicologia a fim de que possa contribuir para a análise e reformulação de práticas educativas e para a ressignificação de atitudes subjetivas".O estudo psicopedagógico atinge seus objetivos quando, ampliando a compreensão sobre as características e necessidades do desenvolvimento de aprendizagem de determinado aluno, abre espaço para que a escola viabilize recursos para atender às necessidades de aprendizagem. Para isso, deve analisar o 
Projeto Pedagógico, sobretudo quais as propostas de ensino e o que é valorizado como aprendizagem. Vale ressaltar de que o fazer psicopedagógico se transforma podendo se tornar uma ferramenta poderosa no auxílio de aprendizagem.

Cabe ao psicopedagogo perceber eventuais perturbações no processo de ensino-aprendizagem, participar da dinâmica da comunidade educativa, favorecendo a integração, promovendo orientações metodológicas de acordo com as características e particularidades dos indivíduos do grupo, realizando processos de orientação. Já que no caráter assistencial o psicopedagogo participa de equipes responsáveis pela elaboração de planos e projetos no contexto teórico prático das políticas educacionais, fazendo com que os professores, diretores e coordenadores possam repensar o papel da escola frente a sua docência e as necessidades individuais de aprendizagem da criança ou da própria ensinagem (BOSSA, 1994, p. 23).

A psicopedagogia já vem atuando com muito sucesso nas diversas Instituições, sejam escolas, hospitais e empresas. A aprendizagem e seu desenvolvimento devem ser olhados como a atividade de indivíduos ou grupos humanos, que mediante a incorporação de informações e o desenvolvimento de experiências, promovem modificações estáveis na personalidade e na dinâmica grupal as quais revertem no manejo instrumental da realidade.

Assim, expor sobre este tema é chamar a atenção dos educadores para realidade do que ocorre nas escolas, mostrando o papel da psicopedagogia diante do mesmo e sua preocupação em encontrar a solução, almejando um ensinoaprendizagem ideal a todo o aluno e toda escola.

\section{Visão teórica de alguns pensadores da psicologia no processo de ensino- aprendizagem}

As diferentes teorias psicológicas, produzidas ao longo da história da psicologia, definem os processos de desenvolvimento e aprendizagem, bem como a relação entre esses processos de modo diferente.

Para alguns teóricos, de base empirista, o desenvolvimento e a aprendizagem são processos idênticos que resultam da ação sobre o indivíduo. Para outras teorias, de base racionalista, o desenvolvimento é resultante do amadurecimento progressivo de estruturas pré-formadas no indivíduo, enquanto a aprendizagem é um processo externo, independente do desenvolvimento.

Os processos de desenvolvimento e aprendizagem, como foram citados, são abordados de modo diferente pelas diversas teorias psicológicas. Buscar-se-á, fazer um 
breve aprofundamento dessas teorias, com vistas em se verificar a contribuição de cada uma delas para a formação do professor no que se refere à compreensão dos processos de ensino e aprendizagem.

Falar na aprendizagem significativa equivale, antes de tudo, a pôr em relevo o processo de construção de significados como elemento central do processo ensinoaprendizagem. $\mathrm{O}$ aluno aprende um conteúdo qualquer... quando é capaz de atribuir-lhe um significado (COLL, 1993, p. 79).

Portanto, a utilização do pensamento significativo deverá ser explorada no processo ensinoaprendizagem muito próximo da vinculação conteúdo com a vida cotidiana, principalmente no caso da aprendizagem infantil. O processo de aprendizagem tem sido estudado de modo direto ou indireto, por teóricos que se dividem basicamente em dois grupos: Os teóricos comportamentais (behavioristas) e os teóricos cognitivistas (interacionalistas).

Algumas teorias psicológicas da aprendizagem como as de Watson, Pavlov e Skinner, todos integrantes do behaviorismo ou comportamentismo, cuja base epsistemológica se funda na concepção de que todo o conhecimento provém da experiência - são concordantes quanto a ideia de que o fator determinante dos processos de desenvolvimento e da aprendizagem é o ambiente. Já para os teóricos comportamentais, o resultado da aprendizagem é uma mudança de comportamento observáveis, causada por fatores externos ou estímulos ambientais ou reforços (punição ou recompensa).

$\mathrm{O}$ behaviorismo (comportamentalismo) se tornou um paradigma na psicologia a partir da década de 1920, mantendo esse status até os anos 1960, com a expansão da intitulada "revolução cognitivista" (COLL, 1995). Apesar dos inúmeros avanços na área, os estudos e as pesquisas comportamentais ainda têm como referencial teórico-prático os trabalhos clássicos desenvolvidos por Burrhus Frederic Skinner (1904-1990) nos Estados Unidos.

De acordo com Skinner, os progressos obtidos na análise experimental do comportamento sugeriam que se podia criar uma tecnologia educacional visando o desenvolvimento de práticas válidas para se promover o ensino-aprendizagem.

A teoria Gestallista procura estudar os processos de aprendizagem a partir das leis da percepção. Em vez de tematizar a aprendizagem como a aquisição de respostas mediante a associação de estímulos, como acontece com o comportamentismo, enfatiza o processo de reestruturação da estrutura cognitiva pela percepção das relações da situação como um todo. Aprender para os adeptos da 
Gestalt é perceber relações e não apenas registrar uma cadeia de respostas a estímulos específicos; aprender é reagir a situações totais significativas e não a elementos isolados.

As teorias cognitivas formam conjuntos de proposições que procuram explicar o processo de construção do conhecimento humano e desenvolvimento da inteligência e, consequentemente, geram informação que nos leva a conhecer como se processa interiormente a aprendizagem. Elas são baseadas em ideias e conceitos desenvolvidos por Jean Piaget (1896-1980)

\section{CONCLUSÃO}

Constatou-se como hipótese de solução as diversas teorias de aprendizagem e a importância da Psicologia da Educação em fornecer subsídios a prática pedagógica de professores, pedagogo e psicopedagogo que favoreceram a compreensão do processo de desenvolvimento e de aprendizagem do aluno.

Portanto, a aprendizagem é um processo dinâmico que envolve a interação do aluno com o meio e, para que ela ocorra é necessário que o educador dê a devida atenção aos fatores que motivam o educando a aprender; entenda que o processo ensino-aprendizagem é uma espiral de conhecimentos, e cada conhecimento serve como base ou pré- na Suíça e por Lev Semynovitch Vygotsky (1886-1934) na Rússia.

$\mathrm{Na}$ perspectiva cognitivista, o processo de aquisição do conhecimento é a aprendizagem em si. Ao contrário dos comportamentais, os alunos são percebidos como agentes ativos que interagem constantemente com o ambiente interno e externo, utilizam suas experiências anteriores, buscam e reorganizam informações, refletem e tomam decisões para que possam adquirir novos conhecimentos.

requisito para a aquisição do seguinte; tenha bom senso crítico ao analisar a fase do desenvolvimento cognitivo da criança para então determinar quais capacidades ela já possui, estimulando o processo de interação social da criança com todas as pessoas que participam do ambiente escolar como forma de promover seu desenvolvimento cognitivo e também estimule o uso da linguagem.

Vale salientar que proporcionar os educandos e educadores de atividades pedagógicas inovadoras mediante a necessidade encontrada, é oportunizá-lo da formação adequada de conhecimento, visando contribuir para formação de sujeitos críticos, capazes e conscientes das 
suas responsabilidades na sociedade onde está inserido.

\section{REFERÊNCIAS}

BOSSA, N. A psicopedagogia no Brasil: contribuições a partir da prática. Porto Alegre: Artes Médicas Sul, 1994.

BANDURA, A. Modificação de comportamento através procedimentos de modelação. In: KRASNER, L. (org). Pesquisas sobre modificações de comportamento. São Paulo: Herder, 1980.

COLL, C. Desenvolvimento psicológico e educação. Porto Alegre: Artmed,1995.

COLL, C. Aprendizagem e construção do conhecimento. Porto Alegre: Artes Médicas, 1993.

FANTANA, D. Psicologia para professores. São Paulo, Loyola, 1998. p. 157.

PILETTI, N. Psicologia educacional. 17 ed. São Paulo: Ática, 1999.

PORTO, O. Bases da Psicopedagogia: diagnóstico e intervenção nos problemas de aprendizagem. 3 ed. Rio de Janeiro: Wak Ed., 2007.

PATTO, M. H. S. A produção do Fracasso Escolar: histórias de submissão e rebeldia. $3^{\text {a }}$ Ed. São Paulo: Queiroz, 2000.

PIAGET, J. A equilibração das estruturas cognitivas. Rio de Janeiro: Zahar, 1976.

SKINNER, F. Sobre behaviorismo. São Paulo: Cultrix, 2000.

- Ciência e comportamento humano. São Paulo: Martins Fontes, 1998. VISCA, J. Psicopedagogia: Contribuições. Rio de Janeiro: Nova Fronteira, 1991.
WOOLFOLK, A. A psicologia da educação. Porto Alegre: Artmed, 2000. WOOLFOLK, A. E. Psicologia $d a$ educação. 7. ed. Porto Alegre: Artes Médicas Sul, 2000. 